\title{
La naturaleza teológica del momento inductivo En tiempos de diversidad, pluralismo y alteridad cultural
}

\author{
CARLOS SCHICKENDANTZ** \\ Centro Teológico Manuel Larraín - Universidad Alberto Hurtado (Chile) \\ cschickend@uahurtado.cl
}

\begin{abstract}
Resumen
La estructura hermenéutica de Gaudium et spes, fundada sobre el método ver-juzgar-obrar, fue motivo de arduos debates en el Vaticano II. El impacto del método en el posconcilio ha sido muy importante en las diversas regiones geográficas de la Iglesia, particularmente en la teología y la pastoral latinoamericanas. El presente artículo ofrece un análisis de varias contribuciones recientes que procuran enriquecer la metodología, especialmente en el momento de auscultación de la realidad. Pone de manifiesto algunos de los progresos que se proponen, destaca adquisiciones que se mantienen y, sobre todo, saca a la luz un asunto necesitado de profundización ulterior: una lectura más teológica de la realidad que implica un cambio en la visión sobre la revelación y que capacita a la teología para asumir los desafíos de la llamada tercera Ilustración (diversidad, pluralismo cultural, alteridad).
\end{abstract}

Palabras clave: método ver-juzgar-obrar, círculo hermenéutico, lugar teológico, Gaudium et spes

\section{The theological nature of the inductive moment In times of diversity, pluralism and cultural otherness}

\begin{abstract}
The hermeneutical structure of Gaudium et Spes, grounded in the see-judge-act method, was the subject of arduous debates during the Second Vatican Council. The influence of the method after the Council has been vital for the Church throughout the world, particularly upon the theological and pastoral work done in Latin America. The present article offers an analysis of recent contributions that aim at enhancing the method, especially when auscultating and intentionally listening to reality. It highlights some proposed developments and underlines enduring convictions. Most importantly, it calls for the exploration of a more theological reading of reality that demands a change in the way revelation is envisioned and understood, and empowers theology to face and assume the challenges of the so-called third Illustration (diversity, cultural pluralism, otherness).
\end{abstract}

Keywords: see-judge-act method, hermeneutical circle, theological place, Gaudium et spes.

\footnotetext{
* Doctor en Teología por la Universidad de Tübingen, Alemania. Actualmente se desempeña como Investigador del Centro Teológico Manuel Larraín, Universidad Alberto Hurtado (Chile). Algunas publicaciones recientes vinculadas al tema: ¿Una transformación metodológica inadvertida? La novedad introducida por Gaudium et spes en los escritos de Joseph Ratzinger (2016); Un cambio en la ratio fidei. Asociación (aparentemente ilícita) entre principios teológicos y datos empíricos (2016).

Este texto es fruto del proyecto de investigación Fondecyt $\mathrm{N}^{\circ} 1150128$.
} 


\section{INTRODUCCIÓN}

La constitución Gaudium et spes ha sido objeto de innumerables análisis en la literatura teológica de estos años. Varios motivos han fundamentado este interés. Uno de ellos, quizás el más importante, ha sido la metodología de tipo inductivo que dicho documento asumió. Entre las novedades que proponía la última versión del llamado Esquema XIII en la cuarta sesión del Concilio, precisamente se contaba la de la estructura hermenéutica del texto que, como afirma C. Theobald, "estaba fundada sobre el método inductivo 'ver-juzgar-obrar' de la Acción católica, introducido como esquema estructurante en la primavera de 1965" (2015: 228) ${ }^{1}$. Los estudios más detallados realizados en las dos últimas décadas han sacado a la luz las perplejidades que esa metodología suscitó entre los padres conciliares. El hecho que la expresión signos de los tiempos aparezca, finalmente, solo una vez en el texto aprobado es un indicio de los debates de entonces. Incluso, es precisamente este debate metodológico el que colaboró a poner en duda la aprobación final del documento dentro del Concilio y, en particular, el carácter asignado: una constitución junto a los tex tos ya aprobados sobre la liturgia, la Iglesia y la divina revelación. Su inédito nombre -constitución pastoral-, difícil de explicar para los autores de la época y sometido a votación en más de una oportunidad en las sesiones finales de 1965, es un reflejo de su novedad metodológica. Los resultados a los que llegó el Concilio en este punto -método inductivo, categoría de signos de los tiempos- son mucho más modestos de lo que a menudo se presume. No pocas veces la bibliografía posterior ha supuesto un desarrollo teológico que, por el contrario, en el documento conciliar es solo germinal. Los sucesos, opiniones de diversas personas, discusiones temáticas y precisiones terminológicas que podrían aducirse para justificar estas afirmaciones son múltiples (Schickendantz, 2013). En particular, las objeciones de los "alemanes", frente a padres conciliares y peritos belgas y franceses, merece una atención particular porque allí se concentraron los más importantes argumentos a favor y en contra de la futura Constitución; argumentos que han sido relevantes también en el posconcilio y que han marcado en buena medida la vida de la Iglesia y de la teología de las décadas posteriores (Schickendantz, 2016a).

\footnotetext{
$1 \quad$ Al respecto, Theobald (2015: 229) señala: "La interpretación de los 'signos de los tiempos' es adquirida de ahora en adelante como principio teológico a partir del cual se organiza el conjunto de la futura Constitución”. Ver también Sander, 2005: 638ss., 644ss., 715.
} 
La opción metodológica aludida representó un salto cualitativo para el magisterio de la Iglesia y la concepción de la teología con una gran repercusión posterior. Es verdad lo que afirma A. Brighenti cuando dice que la metodología heredada de la Acción Católica "es más que un método; es una pedagogía. Más que eso, es sobre todo una forma de ser Iglesia" que, junto a otras iniciativas del Vaticano II, contribuyó significativamente para "el nuevo lugar de la Iglesia en el mundo, para la nueva teología del laicado, para una pastoral encarnada y transformadora, para la militancia ciudadana de los cristianos en la sociedad, en fin, para un compromiso con las grandes causas de la humanidad que son en realidad las causas del Evangelio de vida en abundancia, vivido y anunciado por Jesucristo" (2015: 608).

Es posible verificar en los diálogos y en la bibliografía internacionales que la constitución Gaudium et spes y, en particular, esta metodología, fueron realmente asumidas en los diversos continentes (Brackley \& Schubeck, 2002; Figueroa Deck, 2004; Cahalan, 2011; West, 2014), aunque de una manera diferenciada (Sander, 2005; Faggioli, 2017). Por lo pronto, las teologías de la liberación en sus diferentes formas - en Norteamérica, Sudamérica, Asia y África - tuvieron en esa manera de proceder un "patrón común", un "hilo unificador", no obstante sus diversidades de género, de origen económico, nacional y étnico, cultural y/o religioso, que no deben minusvalorarse (Phan, 2000: 62).

Pero debe reconocerse que, desde esta perspectiva metodológica, América Latina recorrió un camino peculiar en el posconcilio: dicha forma de proceder tuvo mayor repercusión y desarrollo en ella que en otras regiones. La Conferencia de Medellín (1968) asumió creativamente el método de reflexión teológica de la Constitución pastoral. Su característica principal reside en que, a diferencia del Concilio, el método no solo impregnó un documento, sino la "mecánica de trabajo", como fue denominada, de toda la Conferencia, que incluso se plasmó en cada uno de los 16 documentos elaborados. Gracias a Medellín, además, el impacto del método para la configuración de la identidad eclesial latinoamericana en los años siguientes resulta innegable. Como ha afirmado Brighenti (2015), él está en la base de las prácticas eclesiales populares que desembocaron en la opción por los pobres, en la formación de las comunidades eclesiales de base, en la práctica de la lectura popular de la Biblia, en el desarrollo de la pastoral social, la militancia ciudadana y la propia Teología de la liberación. Todas estas expresiones eclesiales, con sus riquezas y limitaciones, representan una cierta novedad teológico-pastoral cualitativa en la historia de la Iglesia y, en buena medida, identifican por su originalidad el caminar y el rostro peculiar latinoamericano. 
Un hecho marcó particularmente el desarrollo posterior a Medellín: los cuestionamientos al método ver-juzgar-obrar en las diversas Conferencias Generales del Episcopado Latinoamericano o con ocasión de ellas. Admitido sin discusiones en el tiempo de Medellín (1968), el método ha sufrido repetidos embates en las Conferencias posteriores, hasta Aparecida (2007), sin excepción. Particular atención recibe la Conferencia de Santo Domingo (1992), porque representa el caso más relevante de este retroceso (Valiente, 2012; Codina, 2013b). Varios autores destacan las dificultades o perplejidades que, al respecto, hubo también en el proceso de preparación hacia Aparecida, incluso en debates durante las mismas sesiones de la Conferencia. Aunque V. Fernández deja claro que "la mayoría de los obispos" deseaba conservar el ver como paso inicial (2007: 136). Brighenti, por su parte, afirma que durante la Asamblea "para que volviese el método ver-juzgar-actuar, se tuvo que aceptar que la parte del ver comenzara con una profesión de fe" (2007: 29). La comparación entre el texto final elaborado, votado y aprobado por la Conferencia de Aparecida -el texto original- y el publicado posteriormente con revisiones hechas en Roma -el texto oficial - llama la atención. Mientras que el número 19 aprobado por los obispos simplemente afirmaba que "este documento continúa la práctica del método 'ver, juzgar y actuar', utilizado en anteriores Conferencias Generales del Episcopado Latinoamericano" (CELAM, 2007: 9), el texto corregido y definitivo es mucho más extenso (De la Serna, 2007; Brighenti, 2016). Introduce una modificación relevante: con expresiones muy recargadas, desfigura el método; es allí casi irreconocible. Importante es lo que indica la modificación: es el síntoma de una preocupación inocultable acerca de la lectura de la realidad, de las perplejidades que le plantea a la Iglesia y a la teología el desafío de un método con un importante componente inductivo. Es "expresión de resistencia a una racionalidad inductiva e histórica" (Brighenti, 2016: 690). Las consideraciones sobre Aparecida - que no desmerecen sus logros- tienen aquí el único propósito - lejos de toda polémica- de mostrar que, desde distintos ángulos, esta forma de proceder, por sus aportes o por las perplejidades que despertaba, ha merecido una gran atención en el debate posconciliar en nuestra región ${ }^{2}$.

En el marco del breve panorama presentado, en la presente contribución me concentro particularmente en tres interesantes publicaciones recientes (Vélez, 2017; Pellegrino, 2017; Pilario, 2016). De esta manera, deseo sacar a la luz nuevos aspectos que están siendo propuestos en relación

2 No faltan contribuciones que muestran el uso, más aún, la "recuperación" a nivel de la Iglesia universal de este método en el pontificado de Francisco (Legorreta, 2016: 621). 
al método, destaco argumentos que ocupan la escena y, sobre todo, este artículo pretende poner de relieve, más allá incluso de estos tres trabajos, qué dimensión, a mi juicio importante, queda pendiente en la reflexión de los variados/as autores/as: un análisis más exacto acerca de la naturaleza teológica del primer momento del método ver-juzgar-actuar. O, expresado desde otra perspectiva, una determinada ampliación en el segundo momento, la mediación hermenéutica, que reclama una revisión de la noción de revelación. Formulado de manera sencilla, la cuestión que reclama un paso adelante, en mi opinión, puede expresarse así: ¿Qué es lo que se ve en el Ver? ¿Qué se percibe en el estudio y discernimiento de la realidad? ¿A qué voces se escucha al prestar atención al contexto histórico-social con el auxilio de las más variadas mediaciones disciplinares y sapienciales? Si es posible discernir la Voz de Dios en las actuales voces humanas, no solo en los testimonios de la propia tradición religiosa (Biblia, tradición, patrística, magisterio, sensus fidelium, etc.), ¿de qué manera esta escucha es reconocida en las explicaciones del primer momento, inductivo, del método y cómo se incorpora esta interpretación en el momento hermenéutico de la metodología teológica?

Este artículo se inserta en una serie de publicaciones que intentan superar la mera "yuxtaposición", "paralelismo" o "dualismo" entre "realidad del tiempo" y "realidad de Dios", entre acontecimientos históricos y Palabra de Dios, que han denunciado varios autores (Schickendantz, 2016b). Desea colaborar al progreso de la reflexión en el asunto que, según C. Geffré, queda pendiente en la meritoria obra de M.-D. Chenu; anota que este habla "explícitamente de revelación continuada", pero que no ha avanzado mucho "en el análisis de la diferencia de estatuto entre la Palabra de Dios consignada en las Escrituras y la Palabra de Dios en y por la historia" (Geffré, 1997: 144-145). El paso adelante que se demanda capacitaría más a la Iglesia y a la teología para afrontar los desafíos de la actual situación internacional caracterizada, entre otros asuntos centrales, por el pluralismo cultural, la diversidad religiosa y el paradigma de la alteridad.

\section{POSIBILIDADES Y LÍMITES DE LA INVESTIGACIÓN ACCIÓN PARTICIPA-} TIVA: O. C. VÉLEZ

El interesante trabajo de Olga Consuela Vélez quien pone de relieve, de manera fundada, la importancia del método de investigación acción participativa en la tarea teológica de nuestro tiempo. El "objetivo primordial" del texto "consiste en articular este método con el quehacer teológico" (Vélez, 2017: 195). En orden a ese objetivo se describen varias de las principales características de este "método inductivo y transformador" (Vélez, 2017: 205), que lo hace particularmente "adecuado para captar la 
realidad como ella es" (Vélez, 2017: 205): la nueva relación entre sujetos/objetos de la realidad que van a ser investigados se constituyen ellos mismos en sujetos investigadores, con lo que se propicia una relación horizontal entre todos los participantes. Esta premisa resitúa el lugar de los investigadores más académicos, ayuda a identificar mejor los problemas, recupera y valora el conocimiento popular, aconseja la selección de diversas técnicas o instrumentos de trabajo (entrevistas, cuestionarios, etc.) que facilitan el encuentro entre personas, la producción de un conocimiento interactivo y social con diversidad de lenguajes y que favorecen la generación de cambios estructurales. Como bien anota Vélez esta metodología, anclada en la experiencia y permeada por una praxis transformadora, aporta nuevas perspectivas epistemológicas, éticas y políticas. De allí que la autora afirme que "podría proponerse como método social para realizar el primer momento del método de la teología de la liberación, la mediación socioanalítica" (Vélez, 2017: 198).

Afirmadas las bondades del método y las posibilidades que ofrece para un mejor conocimiento de la realidad, aspecto central del interesante artículo de Vélez es la inserción del mismo en el proceso del quehacer teológico. En este punto destaco dos series de afirmaciones que son relevantes para la temática de esta contribución. Por una parte, la observación repetida - con variadas expresiones próximas - acerca de que "toda la realidad humana es lugar teológico, es decir, lugar donde podemos descubrir el acontecer de Dios" (Vélez, 2017: 195). Por otra, la importancia decisiva en el quehacer teológico de la "dinámica del círculo hermenéutico donde la fe es el horizonte de cualquier acercamiento a la realidad" (Vélez, 2017: 206).

En referencia al primer aspecto es posible encontrar varias expresiones análogas: afirma que en las realidades terrestres la teología contextual "sabe descubrir en ellas la voz de Dios y se propone interpretarla con los medios adecuados para ello. Toda la realidad... es lugar de revelación, y la teología tiene la tarea de desvelar esa palabra y contribuir a su eficacia en la transformación de la realidad" (Vélez, 2017: 201). Igualmente se dice que son "los mismos participantes en las investigaciones quienes por medio del método investigación acción participativa pueden ofrecer ese lugar teológico - sus propias experiencias- para descubrir en este el querer de Dios y la iluminación de esa realidad desde su voluntad salvífica" (Vélez, 2017: 202). Del mismo modo, la autora escribe: "En consonancia con la revelación de Dios en la historia podemos afirmar que la acción humana no es un simple receptáculo de aplicación de las doctrinas reveladas sino 
que ella misma es lugar teológico donde acontece la revelación” (Vélez, 2017: 204) $)^{3}$.

Importante para las reflexiones que se aportan aquí es la verificación acerca de cómo esas frases se traducen en el método teológico, en otras palabras, cómo esa idea se integra al círculo hermenéutico que se destaca. Por una parte, se caracterizan los tres momentos: "consiste en un partir de la acción humana que corresponde al 'ver', acción que es interpretada, asumida y relacionada en términos teológicos correspondiendo al 'juzgar', para proponer procesos de transformación de esa acción humana percibida previamente en términos del hacer o del "actuar" (Vélez, 2017: 204). Es claro que el método de investigación acción participativa "permite considerar el objeto material de la reflexión teológica”, pero, recuerda Vélez, "hemos de interpretarlo desde el aspecto formal, propiamente teológico, para cumplir con los objetivos propuestos." Esa formalidad es descrita con varias expresiones: "acudiendo a las fuentes irrenunciables del quehacer teológico - Sagrada Escritura y tradición - junto a todo el acervo eclesial, teológico e interdisciplinar que aporta luz sobre las realidades consideradas" (Vélez, 2017: 206); los temas "necesitan ser iluminados con los 'textos de tradición”", las “preguntas que surgen del 'contexto' (praxis histórica)", iluminadas con "textos revelados (a la luz de la fe) desde los pretextos o intencionalidades (reflexión crítica) marcados por la liberación y la búsqueda de transformación de la realidad" (Vélez, 2017: 190).

Si bien se hacen afirmaciones acerca la actualidad de la epifanía de Dios en la realidad ("acontece la revelación"), parece que al caracterizar el círculo hermenéutico no se abandona una posición muy difundida que considera el Ver como un momento no específicamente teológico, que es interpretado teológicamente en el Juzgar solo a partir de las "fuentes irrenunciables" o de los "textos de tradición", los "textos revelados". Aquí ya no aparece claramente como ingrediente constitutivo del Juzgar la misma Palabra de Dios que se transparenta y emerge en los procesos históricos actuales. Un discernimiento realizado gracias, también, al aporte metodológico que se está proponiendo. Esta cierta dualidad es la que inclina a algunos autores a hablar de la existencia de una mera "yuxtaposición" o

\footnotetext{
3 Al respecto es interesante lo dicho por la autora cuando señala, "La posibilidad de esta lectura es consecuencia del Dios que se revela en la historia. Por eso se necesita la labor teológica capaz de discernir los métodos adecuados para tal lectura — sin olvidar que estos son medios y no fin- y la libertad evangélica para liberarse de ideologías en boga que pueden traicionar una captación auténtica del acontecer de Dios en la historia" (Vélez, 2017: 199); “Además de estas mediaciones históricas está la mediación del acontecer presente que sostiene la ininterrumpida locución de Dios en la historia. Por tanto, toda la historia es lugar teológeno (generador de la teología) en su aspecto de materialidad previa a la formalidad teológica" (Vélez, 2017: 200).
} 
"paralelismo" entre "realidad del tiempo" y "realidad de Dios", entre acontecimientos históricos y Palabra de Dios como se ha escrito en la introducción. No faltan frases sobre la "revelación" actual de Dios, que no es de ninguna manera una afirmación obvia como podría constatarse en cualquier manual de teología fundamental en las más variadas lenguas, sino su más clara inclusión al momento de describir el funcionamiento del círculo hermenéutico, que debe hacerse cargo, en palabras de Geffré, "de la diferencia de estatuto entre la Palabra de Dios consignada en las Escrituras y la Palabra de Dios en y por la historia" (1997: 144). Esa Palabra actual de Dios - caracterizada aquí como revelación- debe coordinarse con la Palabra de Dios en los textos de tradición. Planteo estas cuestiones más allá del sugerente texto de C. Vélez y con el deseo de colaborar a un diálogo fructuoso sobre el asunto.

\section{UN VER “CÁLIDO”. LAS HISTORIAS DE VIDA: L. PELLEGRINO}

Preocupaciones próximas al texto de Vélez conducen al teólogo italiano, Luigi Pellegrino (2017), a formular su propia propuesta. Dos objetivos principales pueden individuarse: primero, el de enriquecer el momento del ver con elementos fenomenológicos y hermenéuticos que lo hagan más histórico y menos objetivista. En segundo lugar, lograr "una mayor interacción entre los tres momentos". En ese marco se comprende su propuesta formulada en el título mismo de la contribución: "propone la inserción de las historias de vida de las personas y las comunidades como un camino nuevo de conocimiento de la realidad" (Pellegrino, 2017: 113) ${ }^{4}$.

No obstante, la existencia de una finalidad común, un interés parcialmente diverso diferencia los trabajos de Pellegrino y de la teóloga de Bogotá. Como es sabido, el método ver-juzgar-actuar fue concebido originalmente como un método de reflexión y de acción, una metodología pastoral, así practicada en las diferentes ramas de la Acción Católica. En la década de 1960, con los textos magisteriales y, específicamente, la teología de la liberación se revelará sobre todo como un método de reflexión teológica, que justifica o explica la nueva manera de hacer teología de la que han hablado muchos autores/as en nuestras latitudes. Pellegrino se sitúa del lado del acento de la metodología pastoral, Vélez, más bien, en su rendimiento como forma de proceder teológica.

\footnotetext{
4 Hay que reconocer que su "novedad" es relativa. Hace tiempo que se advierte su presencia en los más diversos contextos regionales y teológicos (Phan, 2000: 49-50). En los trabajos del Centro Teológico Manuel Larraín ya se ha afrontado este tipo de perspectivas de investigación cualitativa (Grieu, 2013: 355-387; Bacher Martínez, 2013: 389-415; Azcuy, 2017: 243-277; Bacher Martínez, 2011: 385-411).
} 
El teólogo italiano afirma que desea acoger "el nuevo paradigma", "el paradigma biográfico-narrativo, que se asume como un nuevo 'ver' la vida, no sólo desde el individuo, sino desde toda una comunidad, como capacidad de entrar profundamente en la realidad". De este modo, piensa, se "amplía" el método ver-juzgar-actuar, sobre todo, se fortalece en el momento del 'ver' ya que dicho ver "no puede ser solamente sustentado y caracterizado por instrumentos y técnicas sociológico-cuantitativas" (Pellegrino, 2017: 120).

A su juicio, "la reflexión teológica está distante de haber tomado conciencia de las implicaciones que resultan del redescubrimiento del relato" (Pellegrino, 2017: 129). De allí que uno de los puntos centrales de su contribución esté dedicado a mostrar las ventajas del ejercicio autobiográficonarrativo. Destaco aquí, sin ánimo exhaustivo, algunos de esos beneficios.

Asumir la orientación narrativo-autobiográfica al interno del método ver-juzgar-actuar, a nivel del "ver" quiere decir, ante todo, "restituir la palabra a los sujetos" (Pellegrino, 2017: 128). Por lo demás, esta tarea, la de la narración, no solo se prevé como una actividad individual, sino también como un ejercicio comunitario, como un momento en la construcción de una comunidad de sujetos: "la comunidad cristiana se constituye en comunidad en la medida en que... lee su historia como historia de vida y de salvación" (Pellegrino, 2017: 128).

Estas prácticas narrativas, además, no solo habilitan a una mejor comprensión de la realidad, sino que constituyen espacios privilegiados de discernimiento - juzgar - y favorecen el hecho que las personas implicadas se conviertan en "protagonistas profundos de cambios en torno a si" (Pellegrino, 2017: 128). De allí que, como se afirma, no solo el momento del Ver se ve beneficiado, sino todo el proceso metodológico.

Lejos de toda mirada ingenua sobre la realidad, ella se presenta siempre como una realidad interpretada: "No se dan hechos desnudos, más bien siempre, cognoscitivamente, interpretados" (Pellegrino, 2017: 125). Por otra parte, el significado mismo del lenguaje, puesto de relieve por el autor, fundamenta la oportunidad de esta propuesta metodológica. No es un nunca un "médium neutral a través del cual la experiencia es llevada a palabra comunicada, sino es la forma misma a través de la cual la experiencia es configurada; es decir, interpretada y modificada del sujeto y del ambiente cultural de su contexto de pertenencia." En este sentido, la narración es "un acto performativo, por medio del cual el sujeto configura y atribuye sentido a sus vivencias propias" (Pellegrino, 2017: 131). El involucramiento personal de quien narra, la toma de distancia que implica, el reconocimiento de otros, etc., son todos ingredientes clave en este proceso de "re-visitación creativa de la propia vida", personal y comunitaria (Pellegrino, 2017: 129). 
A las bondades del ejercicio narrativo para el momento del Ver, Pellegrino destaca la idea del círculo hermenéutico, preocupación central en su texto ${ }^{5}$. Dedica unos párrafos a explicarlo de la mano, sobre todo, de $\mathrm{H}$. G. Gadamer. Precisamente, uno de sus objetivos es destacar la "interacción" de los tres momentos o, en otras palabras, corregir lo que llama uno de los "riesgos mayores": la "yuxtaposición" de las tres fases. "Resulta una yuxtaposición, un 'poner algo junto a otra cosa' sin guardar ninguna relación interna... Hay secuencia sin consecuencia. Cada parte sigue a la otra, pero no hay lógica interna. Hay un agregado de partes, pero no un sistema estructurado y coherente" (Pellegrino, 2017: 117). Este error metodológico afecta a los tres momentos, perjudicando su función específica, la que solo puede realizarse adecuadamente en la integración positiva. El riesgo en el caso del juzgar, advierte, por ejemplo, es que se convierta en un "juicio teológico extrínseco"; en ese caso, el momento teológico aparecería como "un paraguas colocado sobre una situación dada; no asume la mediación de lo humano, más bien se sobrepone a ella." Su tarea específica debe ser, por el contrario, "una interpretación teológico-pastoral de la realidad. Debe hacer una lectura a la luz de la Palabra de Dios" (Pellegrino, 2017: 118).

Aparecen en el texto de Pellegrino frases que indican la emergencia de la Palabra de Dios en los sucesos históricos. La más relevante, quizás, afirma: "También Dios es una autobiografía que se manifiesta a través de los acontecimientos humanos y, no por eso, es menos verdad la realidad humana" (Pellegrino, 2017: 127) ${ }^{6}$. Pero este aspecto no es ulteriormente explicitado, tampoco se explica su significado metodológico y su eventual articulación con otras vías de manifestación de la Palabra. A diferencia del texto de Vélez aquí no hay alusiones explícitas a la Biblia, sino al término

5 "La narración con el método de las historias de vida, no es solamente un apoyo al momento del 'ver' de la trilogía ver-juzgar-actuar, más bien es un apoyo a todo el proceso de planificación pastoral: en el momento del discernimiento y en su práctica comunicativa, enfocando el papel protagónico de los sujetos involucrados, y como momento de vínculo en los distintos momentos de planificación” (Pellegrino, 2017: 126). 6 Pellegrino introduce un comentario al texto de Ex 3,7: como si el mismo Dios asumiera la metodología de tres momentos. Su propuesta, piensa, se inserta en esa dinámica. "Dios mismo hace del ver, junto al escuchar, una actitud primaria para vivir su proyecto de salvación para su pueblo herido y sufriente. En el texto se ve un Dios que libera, con una metodología que la misma Iglesia latinoamericana, ha asumido en los últimos 60 años: "ver" (Yo he visto la opresión de mi pueblo), junto a la "escucha" (he oído los gritos de dolor), "juzgar" (conozco muy bien sus sufrimientos) para tomar decisiones de valor, y luego sigue el "actuar" como proceso de planificación de liberación (Por eso he bajado a librarlo)" (Pellegrino, 2017: 118). 
"Palabra de Dios" sin mayores precisiones; tampoco se emplean las expresiones "revelación" y "lugar teológico"”

\section{DESAFÍOS ACTUALES DEL MÉTODO DESDE EL QUEHACER TEOLÓGICO EN ASIA: D. F. PILARIO}

El teólogo filipino comparte la opinión acerca del significado trascendente de la metodología del ver-juzgar-actuar para la Iglesia y la teología. "Llegó a ser el sello distintivo del espíritu del Vaticano II", anota. Si bien reconoce la importancia del desarrollo acontecido en América Latina, destaca también el servicio prestado a su continente: "Los obispos de Asia (FABC) intentaron adaptarlo al espíritu asiático de armonía y contemplación, pero el contenido de sus documentos puede aún leerse desde la perspectiva del mismo método" (Pilario, 2016: 94).

El objetivo del artículo de Pilario es "trazar los desafíos actuales que tiene que afrontar este método y avanzar algunas propuestas desde la perspectiva de nuestro quehacer teológico en Asia" (Pilario, 2016: 95). Se estructura en tres partes conforme al método. La primera, Ver, advierte sobre el cambio verificado en los "tiempos posmodernos y poscoloniales": un "viraje hacia la cultura" que pone en cuestión "el análisis puramente socio-económico" característico de la primera ola de la teología de la liberación. "La categoría de clase dejó de ser exclusiva y el contexto plural se convierte ahora en el nuevo locus theologicus" (Pilario, 2016: 96). Se verifica un "desplazamiento hacia la pluralización de los contextos y los métodos socio-analíticos en el 'ver' (o leer los signos de los tiempos)" (Pilario, 2016: 96). Constata el autor que hoy existe una mayor conciencia de los recursos culturales, de las intuiciones morales de las tradiciones religiosas, de los valores comunitarios ya presentes, de las filosofías y la sabiduría que se encuentran en canciones, mitos y prácticas, etc.; todas realidades convertidas en "fuentes de reflexión teológica" (Pilario, 2016: 96). La propuesta de Pilario en este campo reside en recuperar una intuición de la primera generación: su “crítica determinante de la 'idolatría del dinero' en el contexto del capitalismo de mercado como causa fundamental de la exclusión social" (Pilario, 2016: 96); una "acumulación de beneficios" que ha invadido los mundos vitales (Pilario, 2016: 97). Por el contrario, no incluir el

\footnotetext{
7 El trabajo del teólogo francés, E. Grieu, se mueve en la misma dirección. Si, por una parte, hay afirmaciones acerca de una "revelación de Dios en los relatos", metodológicamente, en el conjunto, parece que no se va más allá de una reinterpretación de la revelación en los términos de un círculo hermenéutico ya apuntado. Se reconoce, explícitamente, que hay una renovación en la idea de revelación, de "revisitar la Revelación" (Grieu, 2013: 372, 375, 381). Clave para interpretar la mirada de Grieu es su referencia en página 386 a C. Theobald (2009: 265).
} 
duro análisis económico, que caracteriza brevemente, al analizar el contexto actual es, a su juicio, "festejar los fetichismos posmodernos de la diferencia y la pluralidad" (Pilario, 2016: 98) ${ }^{8}$.

Una reflexión sobre el "juzgar” ocupa la segunda parte del artículo. Él "se ha considerado tradicionalmente como una aplicación vertical de principios a situaciones concretas", puesto que la misma teología ha sido entendida "como un proceso deductivo a partir de dogmas y doctrinas (pre)establecidas". Desde ese diagnóstico se comprende su propuesta: "El desafío del futuro método teológico es encontrar un lugar en el que quepan las voces de la realidad en nuestra explicación de los denominados principios cristianos". Según Pilario, la contribución que la reflexión asiática aporta a la revisión del método es "insertar la 'contemplación' como parte del proceso que la FABC denomina la 'espiral pastoral”", es decir, "el análisis social de inmersión/exposición-contemplación-planificación". Esta inserción significa que "el discernimiento teológico incluye intrínsecamente escuchar las voces del otro y la voz del Totalmente Otro" (Pilario, 2016: 98-99).

En un punto clave para el propósito de esta contribución, Pilario afirma: "Al 'juzgar' y discernir no solo necesitamos escuchar la voluntad de Dios oída desde los lugares altos de la Escritura y la doctrina, sino también las voces silenciosas de Dios en las comunidades de base" (Pilario, 2016: 101). Refiere aquí no solo a las comunidades cristianas, sino en el marco multirreligioso del Asia a comunidades que tiene su fuente no solo en la Biblia, sino en otros tantos textos y fuentes de sabiduría. La "inspiración divina puede oírse" no solo a partir de grupos bíblicos, sino en la lucha de movimientos populares, en los rituales de pueblos indígenas, en la actividad de movimientos ecologistas, en la vida diaria de infinidad de personas, etc. (Pilario, 2016: 101).

Con expresiones análogas está afirmado aquí un punto importante ya advertido en las contribuciones analizadas de Vélez y Pellegrino. Pero no hay indicaciones más precisas en el texto de Pilario; no queda especificada más exactamente la naturaleza de dicha "inspiración divina", ni articulada su relación con la Biblia y otras instancias de testimonio de la Palabra de Dios. La superación del método unilateralmente deductivo, justamente criticado por el teólogo filipino, en buena medida está en juego en estas precisiones que el texto no ofrece. La frase formulada parece acertada en

\footnotetext{
8 La expresión no minusvalora, en sí misma, esa diferencia y pluralidad. Por el contrario, dos buenos ejemplos del autor atestiguan esto: los trabajos dedicados al asunto de la pluralidad y especificidad del panorama religioso asiático y a la importancia de los espacios contextuales en un mundo globalizado (Pilario, 2002a: 71-98; 2015: 279-318).
} 
su dirección, pero todavía insuficiente: "El desafío del futuro método teológico es encontrar un lugar en el que quepan las voces de la realidad en nuestra explicación de los denominados principios cristianos". El camino a recorrer, justamente para superar el carácter unilateralmente deductivo que critica con acierto, debe ir más allá de la "explicación" de los "principios cristianos". Por tanto, está señalada la dirección. Pero, es necesaria una conceptualización metodológica ulterior, precisamente para "repensar la función de las experiencias y de la reflexión de las personas... para la (re)formulación de las proposiciones dogmáticas cristianas y de las estructuras pastorales" (Pilario, 2016: 93-94). Por otra parte, las críticas a un tipo de teología caracterizado por la "hegemonía de expertos", por una conceptualización hermética y poco comprensible y por la carencia de estructuras eclesiales concretas de escucha del sentir de los fieles quedan, por el contrario, bien contextualizadas.

La tercera parte del artículo, sobre el Actuar, canaliza las ideas expuestas en los dos momentos anteriores: privilegia las prácticas cotidianas, los actos de resistencia de la gente común, de la red heterogénea de trabajadores, emigrantes, movimientos sociales, pueblos dominados, etc. Así se entiende su propuesta de que la Iglesia y la teología recuperen "los diferentes modos comunes religioso-culturales, locales e indígenas, mediante los que los pueblos se resisten ingeniosamente y en este proceso avanzan hacia su propio bienestar y el bienestar de los demás" (Pilario, 2016: 104) ${ }^{9}$. El conjunto de las reflexiones del artículo está orientado a recuperar la "sacudida redentora", objetivo que, destaca Pilario, impulsó a Cardjin y a los primeros apóstoles obreros a los comienzos del método ver-juzgarobrar.

\section{AlguNAS REFLEXIONES CONCLUSIVAS}

Con el trasfondo de los artículos referidos, deseo concluir con una serie de reflexiones. En primer lugar, una constatación fundamental: como ha sido destacado, el método ver-juzgar-actuar está en el corazón mismo de Gaudium et spes, en buena medida resume el espíritu del Vaticano II, ha estructurado la forma de pensar la fe y organizar la reflexión y la planificación de la pastoral en América latina y el Caribe, además, está en la base de varias de las originales experiencias eclesiales de estas décadas, como la lectura popular de la Biblia. Estos argumentos y otros que podrían añadirse aconsejan una profundización, un desarrollo ulterior de una manera de

\footnotetext{
9 En esta línea se sitúa su interesante panorama sobre los diversos tipos de teología en Filipinas y su aporte mediante una noción de cultura más procesual y dinámica (Pilario, 2002b: 59-78).
} 
proceder que, en esta forma y envergadura, tiene solo cinco décadas en la historia de la Iglesia. Constituye un salto cualitativo importante en el desarrollo de la metodología teológica, precisamente, por su momento inductivo. Así se explican y comprenden bien las incertidumbres de autores de la talla de Rahner y Congar, por citar a algunos de los más destacados teólogos del siglo XX. "No es fácil decir qué es una Constitución pastoral”, escribía el teólogo alemán en 1967 (Rahner, 1967: 613). En ese mismo contexto temático observaba Yves Congar: "Se nos plantea el problema de precisar qué es lo que la historia aporta a nuestro conocimiento", advirtiendo la necesidad de "abrir un nuevo capítulo de epistemología teológico pastoral" (Congar, 1970: 89). Es la dificultad que, breve y precisamente, caracterizara en tiempo reciente Peter Hünermann: "no se veía cómo podían conjugarse afirmaciones histórico-contingentes y afirmaciones de principios" (Hünermann, 2012: 323). Walter Kasper, por su parte, ha afirmado que el tema, indefinido en los debates conciliares, permanece irresuelto en la actualidad (Schickendantz, 2014: 162-163). De allí que, con perspectiva histórica, deba constatarse que este salto cualitativo en la metodología teológica es todavía incipiente, necesitado de desarrollo y maduración.

En segundo lugar, una reflexión sobre el uso de "lugar teológico". Muy probablemente gracias a su utilización en los documentos de Medellín, la categoría de lugar teológico adquirió ciudadanía en la teología latinoamericana. Un aspecto importante puede advertirse en la historia del uso de esta noción, verificable ya en la misma obra de Gustavo Gutiérrez, La Teología de la liberación (1990: 63, 68). Parece que, inadvertidamente, la categoría se "independizó" de su contexto de origen, esto es, "un conjunto de principios organizativos estándar que guían la tarea teológica" (Wicks, 1992: 833), expuestos en la obra de Melchor Cano de 1563 que ha influido de manera decisiva en la metodología teológica posterior. Precisamente, en ese contexto metodológico los "lugares teológicos propios" de la teología constituyen "domicilio de todos los argumentos teológicos, de donde los teólogos puedan sacar todas sus argumentaciones bien para probar bien para refutar" (Cano, 2006: 9). Junto a ellos, el dominico español añadió de una forma novedosa los llamados "lugares teológicos ajenos" (razón natural, filosofía, historia). Esta estructura eclesial del creer y argumentar - que incluía diez lugares en Cano- es esencialmente "una relación de fuentes", en la cual ningún lugar puede ser considerado de modo aislado, ni tampoco asumir un monopolio indebido. Se trata de una red epistemológica en la cual cada lugar teológico posee una autoridad específica y diversa, acorde a la medida o grado en que constituye una instancia de testimonio de la Palabra de Dios, punto de partida de toda teología (Wicks, 
1992: 833-834). No es lo mismo la Escritura, que la enseñanza de un concilio o el consenso de los teólogos y teólogas o el sentido de la fe de todos los creyentes. Los lugares teológicos son fuentes cognoscitivas, puntos de referencia que dan que pensar, a partir de los cuáles se argumenta desde una mirada específica, pero no constituyen solo un lugar hermenéutico que permite que la revelación de más de sí. Constituyen también una red de autoridades - decisivo es el origen del testimonio: deriva de un ser humano o viene de Dios- para pensar y argumentar teológicamente.

Como he indicado, en la bibliografía latinoamericana sobre esta categoría en estas décadas pueden detectarse estas dos características: por una parte, la no atención explícita al conjunto de la estructura del creer, a la consideración de un lugar teológico en el marco de un sistema de lugares teológicos. En otras palabras, refiere a un "aislamiento" o "independización" de la noción de lugar teológico, autonomizada de su contexto de origen que la insertaba en una red de múltiples instancias de transmisión de la Palabra de Dios. Por otra parte, la insuficiente reflexión metodológica acerca de la especificidad propia de la emergencia de la Palabra en los acontecimientos históricos actuales; lo que Hünermann caracteriza como "asociación en apariencia metodológicamente ilícita entre principios y datos empíricos" (Hünermann, 2012: 333). O en palabras de Geffré, acerca "de la diferencia de estatuto entre la Palabra de Dios consignada en las Escrituras y la Palabra de Dios en y por la historia" (Geffré, 1997, 144145). Solo cuando se advierte y explica metodológicamente ese estatuto, esa diferencia y su vinculación intrínseca se abandona una perspectiva deductiva, que no hace justicia a una de las vías por las que la Palabra se transmite. En este sentido, en la tarea teológica, en la mediación hermenéutica, no solo se ve la realidad "a la luz de la Palabra", sino que también se discierne cómo y en qué medida en las experiencias humanas y los acontecimientos históricos se transparenta, emerge la misma Palabra de Dios. Es necesario advertir el matiz. Por ello, no son suficientes las repetidas frases de que Dios obra en la historia, se revela en ella, u otras análogas, la pregunta es por su estatuto metodológico, por su fuerza argumentativa, por su autoridad teológica en la red epistemológica. Que la obra de Cano haya pasado desapercibida, de hecho, es un síntoma que puede indicar el problema. Se adoptó "su" categoría y (casi) nunca se hizo referencia a él y a su red epistemológica, su "relación de fuentes". Por lo demás, no estoy proponiendo retomar ese esquema en los términos del dominico español, incluso porque, precisamente en relación a la auctoritas bistoriae bumanae como lugar teológico, se ha producido un salto cualitativo, inimaginable para los teólogos del siglo XVI; para Cano la historia es solo un instrumento subordinado de conocimiento, un lugar "ajeno", que prueba lo que ya se sabe (Schickendantz, 2014: 166-168). 
En tercer lugar, por razones de espacio no es posible aquí realizar un paso ulterior, pero sí deseo enunciarlo. La insuficiencia metodológica apuntada estaría presente en los más importantes trabajos metodológicos, incluidos los pertenecientes a la teología de la liberación (Costadoat, 2016; Costadoat, 2017). Cuando, por ejemplo, J. B. Libanio afirma que el "carácter específico de la teología sería la mediación hermenéutica, que interpreta el dato procesado por las ciencias sociales a la luz de la Escritura" (Libanio, 2010: 31), o los hermanos Boff escriben que en el círculo hermenéutico o interpelación mutua entre pobre y palabra, reconocen que "en esa dialéctica la preferencia le corresponde a la palabra soberana de Dios", entendida allí como "revelación bíblica" (Boff \& Boff, 1986: 35, 45-46), estamos distantes todavía de la idea de un acontecimiento histórico como un posible lugar teológico propio. El ver es caracterizado como un momento sociológico - al interior de un proceso de argumentación teológica, es verdad-y la mediación hermenéutica se pone a la búsqueda de lo "qué dice la palabra de Dios sobre" esa realidad, "a la luz de la fe", a menudo identificada con la Escritura, que no destaca la emergencia de la Palabra en la realidad misma al momento de explicar el círculo hermenéutico. $\mathrm{Pa}$ rece necesario pensar una vinculación más estrecha entre la mediación socio-analítica y la mediación hermenéutica.

Es correcto decir que la especificidad de la teología viene dada por el momento hermenéutico, pero, a la vez hay que subrayar, por un lado, la emergencia de la Palabra en la realidad misma, gracias también a la observación cualificada concretada con la ayuda de los más diversos instrumentos disciplinares y, por otro lado, que esa mediación no es concretada solo a la luz de la Escritura. Siendo la Biblia el lugar de luz decisivo, la norma normans non normata, no es la única vía de transmisión de la Palabra. Como en muchos autores/as no faltan también en los aquí citados, frases acerca de que Dios habla en la historia, o expresiones parecidas, pero éstas no parecen tener una inserción adecuada, explícita en el método teológico. Puede quedar abierta aquí la cuestión de si una verificación semejante no podría hacerse en los mismos textos de Gutiérrez o en muchos otros autores, pero eso es tema de otro artículo. En este sentido, los tres interesantes textos analizados -Vélez, Pellegrino, Pilario- constituirían, bajo este respecto, solo un ejemplo de una cuestión más amplia.

En cuarto lugar. En los trabajos sobre la teología de los signos de los tiempos o en los referidos al método ver-juzgar-actuar es posible comprobar dos tendencias o búsquedas más o menos bien definidas. Por una parte, la ampliación del campo de visión de la realidad gracias a métodos de investigación cualitativa, entre otras formas de proceder hoy ensayadas. Los aportes analizados en esta contribución dan cuenta de lo oportuno de esta renovada forma de acceso a una realidad histórico-contextual que se 
muestra, progresivamente, más compleja gracias a las múltiples miradas especializadas. Por otra parte, la búsqueda de profundizar la lectura teológica de la realidad poniendo de relieve, más de lo que se ha hecho hasta ahora, la articulación entre la Palabra de Dios y los acontecimientos históricos y su inserción en el concierto de las Palabras de Dios que llegan a la humanidad por las más diversas vías de transmisión. Es oportuno advertir que no se trata de dos búsquedas carentes de vinculación, sino, por el contrario, intrínsecamente relacionadas. Solo una comprensión lo más adecuadamente posible de lo que acontece en las distintas esferas de la vida humana permite discernir con menos posibilidades de error la nueva $\mathrm{Pa}$ labra que Dios pronuncia a través de o mediante las experiencias humanas y los acontecimientos históricos. Porque las voces humanas y la Voz de Dios, análogamente a la estructura de las dos naturalezas de la unión hipostática, no están separadas ni confundidas, sino estrechamente articuladas. Son voces diferentes, pero inseparables. "Tienen entre sí una relación semiótica", es decir, una vinculación que se reconoce y comprende por signos (Sander, 2005: 727). En la profundización ulterior y el enriquecimiento recíproco de ambos aspectos o búsquedas — nivel histórico y nivel teológico- parece estar una clave del renovado servicio de esta metodología, de una teología de los signos de los tiempos.

Quinto. Con esta lectura teológica de los sucesos históricos —una adecuada articulación de trascendencia e inmanencia - la autonomía de la realidad, tan apreciada por nuestros contemporáneos, no corre ningún peligro. Como afirma C. Taylor: "la gran invención de Occidente fue la de un orden inmanente a la Naturaleza, cuyo funcionamiento pudo ser entendido y explicado de manera sistemática en sus propios términos"; en nuestro tiempo dicho "orden inmanente se vuelve algo más que una teoría, más bien, se convierte en el telón de fondo de todo nuestro pensamiento" (2014: 41). No representa una casualidad que dicho principio de autonomía haya devenido una idea importante en la Constitución pastoral del Concilio: "La justa autonomía de la realidad terrena" (GS 36). El mismo texto conciliar que invita a una lectura teológica de la historia, promueve y garantiza la correcta idea de un orden inmanente "entendido y explicado de manera sistemática en sus propios términos" (Taylor). Por ello mismo la primera tarea de un discernimiento de los signos de los tiempos queda bien delineada: es necesario "conocer y comprender el mundo en que vivimos, sus esperanzas, sus aspiraciones y el sesgo dramático que con frecuencia le caracteriza" (Concilio Vaticano II, 2000: GS 4). El quehacer teológico requiere todos los medios puestos a disposición por las más variadas formas científicas, tradiciones y saberes populares, todo tipo de metodología y vía de acceso a la realidad que permita una mejor y más acabada 
comprensión de su complejidad, profundidad, diversidad y riqueza. Supone no solo la utilización de instrumentos metodológicos, sino sobre todo una gran sensibilidad para la escucha de las palabras humanas, en el mayor número y con la mejor calidad posible. El discernimiento de la Voz de Dios en las actuales voces humanas - de la Palabra en las palabrasrequiere la mejor comprensión posible de los procesos históricos en desarrollo. En este sentido, las contribuciones comentadas en este artículo representan un paso adelante, positivo en la profundización de una metodología de escucha - Ver- que ha sido tan relevante para las iglesias y las teologías, no solo en América Latina.

Sexto. En opinión del teólogo indio, F. Wilfred, el hecho más importante del Vaticano II no lo constituye simplemente la idea de una Iglesia que deviene mundial, sino la "visión teológica de que la revelación y autocomunicación de Dios tiene verdaderamente un alcance católico y universal". Este es el "punto clave en la recepción del Concilio en Asia", que permite mirar de una nueva manera las experiencias de millones de personas que pertenecen a otras tradiciones culturales y religiosas (Wilfred, 2012: 179). Es precisamente sobre esta convicción —el Espíritu que se derrama sobre toda la tierra- que la Constitución Gaudium et spes fundaba la lectura de los signos de los tiempos: "El Pueblo de Dios, movido por la fe, que le impulsa a creer que quien lo conduce es el Espíritu del Señor, que llena el universo, procura discernir en los acontecimientos, exigencias y deseos (...) los signos verdaderos de la presencia o de los planes de Dios" (Concilio Vaticano II, 2000: GS 11). Es una convicción de la Constitución, además, que en todas las personas "obra la gracia de modo invisible"; de allí que afirme que "debemos creer que el Espíritu Santo ofrece a todos la posibilidad de que, en la forma de Dios conocida, sean asociados a este misterio pascual" (Concilio Vaticano II, 2000: GS 22). Estas perspectivas del Concilio, aquí solo enunciadas, afirman la universalidad de la oferta de la gracia como autocomunicación de Dios, descentran la Iglesia, ponen las bases para reconocer un estatuto teológico a todas las tradiciones culturales y religiosas de la humanidad, fundamentan la idea de la manifestación o revelación de Dios en las experiencias humanas y en los acontecimientos históricos. Está abierta una revisión y/o ampliación de la noción análoga de revelación (Schickendantz, 2016b: 181-184).

En séptimo lugar. Estas perspectivas colaboran a enfrentar los desafíos actuales que múltiples autores destacan como centrales en nuestra situación cultural, global. V. Codina y A. Brighenti, por ejemplo, ponen de relieve las responsabilidades que competen a la Iglesia y a la teología en el marco de la llamada tercera Ilustración caracterizada ya no como la primera - en términos de autonomía del sujeto-, ni como la segunda Ilustración - preocupada sobre todo por la justicia y los pobres, no solo por la razón 
autónoma-, sino por las siguientes palabras clave: pluralismo, complejidad de subculturas, paradigma de la alteridad; una época que vive y "dialoga con la diversidad y el pluralismo, con los otros, las otras y el Otro" (Codina, 2013: 86). Si el desafío, entonces, reside en la "complementación" de la primera y segunda Ilustración con la tercera, cuyo núcleo es "la seria tematización del 'otro'... como el totalmente 'otro', el diferente" (Brighenti, 2010: 170), cobra mucho sentido el intento de validar la autoridad teológica de los acontecimientos históricos y de las experiencias humanas en la metodología teológica. Esta tarea representaría una manera adecuada, desde la metodología teológica, de hacerse cargo de este nuevo paradigma, caracterizado por el pluralismo cultural y religioso, por la "irrupción del otro como "diferente" (Brighenti, 2010, 172; Pilario, 2016: 98-99).

Como recuerda Brighenti, nuevos desafíos o nuevas preguntas requieren "ampliación de horizontes, con imperativos concretos para la epistemología y el método de las ciencias en general, incluida la teología" (2010: 189). No hay duda que el salto cualitativo para la elaboración de la primera teología no europea fue hecho posible por la conciencia contextual, gracias al momento inductivo. Una profundización en esta línea estaría a la altura de los procesos de inculturación en las diversas regiones de la tierra y acordes al paradigma de la alteridad, de toda alteridad, especialmente de la alteridad negada. Preguntarse por la autoridad teológica de las experiencias históricas, no solo por la autoridad de los sucesos y textos de la propia tradición religiosa, por la (posible) Voz de Dios en las actuales voces humanas, es otorgar el argumento más profundo en teología para atender al diálogo inter y transdisciplinar, al diálogo entre culturas y confesiones, al respeto y aprecio por toda alteridad (personas, textos, tradiciones, ritos, éticas, credos, poesías, etc.). Ella deviene espacio de una posible teofanía, una posible instancia de testimonio de la Palabra de Dios. La Iglesia y la teología están esencial y constitutivamente abiertas a la alteridad "ajena", no "propia", a un "lugar teológico ajeno", que gracias a un proceso de discernimiento es posible identificar como un "lugar teológico propio" - locus theologicus proprius - en la terminología de Melchor Cano (2006). Es el camino solo inicialmente abierto por Gaudium et spes que requiere ulteriores precisiones metodológicas consensuadas. La expresión utilizada a menudo en la bibliografía acerca de que la historia es un lugar teológico es todavía una expresión genérica, que dice poco sobre el exacto estatuto de la Palabra en la historia y su vinculación y articulación con los otros lugares teológicos - propios y ajenos- que conforman la red epistemológica a partir de la cual el quehacer teológico piensa y argumenta.

Last but nos least. Esta mirada favorece un acceso a las realidades humanas más respetuoso, menos dominador, más atento y receptivo, más 
místico: a la escucha de una posible Palabra de Dios en la historia, que no proviene solo de la propia tradición cultural y religiosa, pero que se discierne gracias a ella.

\section{REFERENCIAS}

-Azcuy, V. (2017). El Movimiento contra la Tortura Sebastián Acevedo. Estudio de caso en el horizonte de una teología de los signos de los tiempos. En V. R. Azcuy, D. García \& C. Schickendantz (Eds.), Lugares e interpelaciones de Dios. Discernir los signos de los tiempos (pp. 243-277). Santiago: Editorial de la Universidad Alberto Hurtado.

-Bacher Martínez, C. (2011). Teología pastoral Inter Loci. Una disciplina teológica ante el aporte de las experiencias creyentes en escenarios sociales contemporáneos. Teología, 106, 385-411.

-Bacher Martínez, C. (2013). Zarzas que arden. Aportes del estudio teológicopastoral de casos a una teología de los signos de los tiempos. En V. R. Azcuy \& C. Schickendantz \& E. Silva (Eds.), Teología de los signos de los tiempos latinoamericanos (pp. 389-415). Santiago: Editorial de la Universidad Alberto Hurtado.

-Boff, L. \& Boff, C. (1986). Cómo hacer teología de la liberación. Madrid: Ediciones Paulinas.

-Brackley, D. \& Schubeck, T. (2002). Moral Theology in Latin America. Theological Studies, 63, 123-160.

-Brighenti, A. (2007). Crónica del desarrollo de la V Conferencia. En Amerindia (Ed.), Aparecida. Renacer de una esperanza (pp. 25-34). Recuperado de http://es.scribd.com/doc/133799345/Amerindia-2007-Aparecida-Renacer-de-Una-Esperanza.

-Brighenti, A. (2010). Epistemología y método en teología. Nuevas interpelaciones para la teología latinoamericana. En J. Legorreta (Coord.), Las ciencias sociales en la teología latinoamericana (pp. 163-190). México D.F.: Ediciones Dabar.

-Brighenti, A. (2015). Método ver-julgar-agir. En J. Decio Passos \& W. Lopes Sanchez (Coord.), Dicionário do Concílio Vaticano II (pp. 608-615). São Paulo: Paulinas.

-Brighenti, A. (2016). Documento de Aparecida: o texto original, o texto oficial e o Papa Francisco. Revista Pistis \& Práxis, 8(3), 673-713.

-Cahalan, K. (2011). Locating Practical Theology in Catholic Theological Discourse and Practice. International Journal of Practical Theology, 15, 1-21.

-Cano, M. (2006). De locis theologicis (J. Belda Plans, Trad.). Madrid: BAC.

-Concilio Vaticano II (2000). Concilio Ecuménico Vaticano II. Constituciones, Decretos y Declaraciones. Madrid: BAC.

-CELAM (2007). V Conferencia General del Episcopado Latinoamericano y el Caribe. Documento conclusivo Aparecida. Santiago de Chile: $\mathrm{CECH}$. 
-Codina, V. (2013). Las iglesias del continente 50 años después del Vaticano II. En Congreso Continental de Teología (Ed.). 50 años del Vaticano II (pp. 8192). Bogotá: Paulinas.

-Codina, V. (2013b). Teología de la Liberación 40 años después. Balance y perspectivas. Horizonte, 11(32), 1357-1377.

-Congar, Y. M. (1970). Situación y tareas de la teología hoy. Salamanca: Sígueme.

-Costadoat, J. (2016). El 'lugar teológico' en Jon Sobrino. Theologica Xaveriana, 181, 23-49.

-Costadoat, J. (2017). ¿Hacia un nuevo concepto de revelación? La historia como "lugar teológico" en la Teología de la liberación. En V. R. Azcuy, D. García \& C. Schickendantz (Eds.), Lugares e interpelaciones de Dios. Discernir los signos de los tiempos (pp. 105-132). Santiago: Editorial de la Universidad Alberto Hurtado.

-De la Serna, E. (2007). ¿No será mucho? Los cambios al Documento de Aparecida. Recuperado de http://www.curasopp.com.ar/posaparecida/d09.php

-Faggioli, M. (2017). An Interrupted Reception of Gaudium et spes. The Church and the Modern World in American Catholicism. En M. Faggioli (Eds.), Catolicism and Citizenship (pp. 94-122). Collegeville, MN: Liturgical Press.

-Fernández, V. (2007). Aparecida. Guía para leer el documento y crónica diaria. Buenos Aires: San Pablo.

-Figueroa Deck, A. (2004). A Latino Practical Theology. Mapping the Road Ahead. Theological Studies, 65, 275-297.

-Geffré, C. (1997). Théologie de l'incarnation et théologie des signes des temps chez le pére Chenu. En J. Doré, J. Fantino, Institut catholique de Paris \& Centre d'études du Saulchoir (Ed), Marie-Dominique Chenu. Moyen-Âge et modernité (pp. 131-153). Paris: Centre d'études du Saulchoir, Cerf.

-Grieu, E. (2013). La Iglesia en la escuela de los creyentes más humildes. La importancia de los relatos de vida. En V. R. Azcuy, C. Schickendantz \& E. Silva (Eds.), Teología de los signos de los tiempos latinoamericanos. Horizontes, criterios y métodos (pp. 355-387). Santiago: Editorial de la Universidad Alberto Hurtado.

-Gutiérrez, G. (1990). Teología de la liberación. Perspectivas (Decimocuarta edición). Salamanca: Ediciones Sígueme.

-Hünermann, P. (2012). Perplejidad del lenguaje ante el Concilio Vaticano II. Concilium, 346, 319-333.

-Legorreta, J. (2016). Eclesiología latinoamericana en el pensamiento del papa Francisco. Revista Pistis \& Práxis, 8(3), 613-630.

-Libanio, J. B. (2010). Balance crítico de la relación entre teología y ciencias sociales. En J. Legorreta (Coord.), Las ciencias sociales en la teología latinoamericana (pp. 11-31). México D.F.: Ediciones Dabar.

-Pellegrino, L. (2017). Las historias de vida en el método de planificación pastoral ver-juzgar-actuar. Veritas, 36, 113-133.

-Phan, P. (2000). Method in Liberation Theologies. Theological Studies, 61, 40-63. -Pilario, D. F. (2002a). 'Locus Theologicus'. Place, Theology and Globalization. Bijdragen, International Journal in Philosophy and Theology, 63, 71-98. 
-Pilario, D. F. (2002b). Hacer una teología contextual. Hacia la conversación sobre el método en el contexto filipino. Voces, 20, 59-78.

-Pilario, D. F. (2015). Is Asia a 'Post-Religional' Society? The Post-Religional Paradigm and its Others. Horizonte, 13(37), 279-318.

-Pilario, D. F. (2016). A vueltas con el método ver-juzgar-actuar. Concilium, 364, 93-105.

-Rahner, K. (1967). Zur theologischen Problematik einer 'Pastoralkonstitution'. En K. Rahner, Schriften zur Theologie. Vol 8 (pp. 613-636). Einsiedeln: Benziger Verlag.

-Sander, H.-J. (2005). Theologischer Kommentar zur Pastoralkonstitution über die Kirche in der Welt von heute Gaudium et spes. En P. Hünermann \& B.-J. Hilberath (Eds.), Herders Theologischer Kommentar zum Zweiten Vatikanischen Konzil. Band 4 (pp. 581-886). Freiburg i.Br.: Herder.

-Schickendantz, C. (2013). Una elipse con dos focos. Hacia un nuevo método teológico a partir de Gaudium et spes. En V. R. Azcuy, C. Schickendantz \& E. Silva (Eds.), Teología de los signos de los tiempos latinoamericanos. Horizontes, criterios y métodos (pp. 53-87). Santiago: Editorial de la Universidad Alberto Hurtado.

-Schickendantz, C. (2014). Autoridad teológica de los acontecimientos históricos. Perplejidades sobre un lugar teológico. Teología, 115, 157-183.

-Schickendantz, C. (2016a). ¿Una transformación metodológica inadvertida? La novedad introducida por Gaudium et spes en los escritos de Joseph Ratzinger. Teología y Vida, 57, 9-37.

-Schickendantz, C. (2016b). Un cambio en la ratio fidei. Asociación (aparentemente ilícita) entre principios teológicos y datos empíricos. Teología y Vida, $57,157-184$.

-Taylor, C. (2014). La era secular (Tomo I). Barcelona: Gedisa.

-Theobald, C. (2009). La réception du concile Vatican II, I, Accéder à la source. Paris: Cerf.

-Theobald, C. (2015). Le concile Vatican II. Quel avenir? Paris: Cerf.

-Valiente, E. (2012). The Reception of Vatican II in Latin America. Theological Studies, 73, 795-823.

-Vélez, O. (2017). El quehacer teológico y el método de investigación acción participativa. Una reflexión metodológica. Theologica Xaveriana 183, 187-208.

-West, G. (2014). Liberation Hermeneutics after Liberation in South Africa. Studies in World Christianity and Interreligious Relations, 48, 341-381.

-Wicks, J (1992). Lugares teológicos. En R. Latourelle \& R. Fisichella (Eds.), Diccionario de Teología fundamental, (pp. 833-834). Madrid: San Pablo.

-Wilfred, F. (2014). Reception of Vatican II in Asia. En S. G. Kochuthara (Ed.), Revisiting Vatican II. 50 Years of Renewal (pp. 168-179). Bangalore: Dharmaram Publications.

Sumario: Introducción; 1. Posibilidades y límites de la investigación acción participativa: O. C. Vélez; 2. Un ver 'cálido'. Las historias de vida: L. Pellegrino; 3. Desafíos actuales del método desde el quehacer teológico en Asia: D. F. Pilario; Algunas reflexiones conclusivas; Referencias. 